1. REFLEXIONES SOBRE LA TRANSICIÓN ESPAÑOLA A LA DEMOCRACIA

MANUEL RAMÍREZ

Catedrático de Derecho Político

Universidad de Zaragoza 
$\vdots$ 


\title{
1. REFLEXIONES SOBRE LA TRANSICIÓN ESPAÑOLA A LA DEMOCRACIA
}

\author{
POR \\ MANUEL RAMÍREZ \\ Catedrático de Derecho Político \\ Universidad de Zaragoza
}

Aunque mi afición por la historia político-constitucional de España acaso me hubiera obligado a ello, la verdad es que no he profundizado en las veces y en los contenidos de las obras específicamente destinadas a estudiar transiciones. Pienso que, por paradoja, son escasas precisamente en un país que, al menos desde comienzos del siglo xIX, lleva "transitando" casi continuamente. En todo caso, demasiados tránsitos y, sin embargo, pocas respuestas documentadas sobre sus auténticos protagonistas o sobre los sucesivos cúmulos de acontecimientos que, en cada momento histórico, nuestro país ha vivido una transición. Por sólo recurrir a un ejemplo, pienso que, a estas alturas y a pesar de lo ya mucho dicho sobre la segunda República Española, todavía cabe la pregunta de quién la trajo a España. Un marxista de catón tendría la respuesta inmediata: la demanda popular, pacífica o violentamente expresada. Para quien hace mucho tiempo que no cree en catones, la cosa no está tan clara. ¿Qué obligó realmente a Alfonso XIII a abandonar España tras unas simples elecciones municipales? ¿Qué papel jugó en aquel exacto momento el ejército? ¿Y los restantes poderes fácticos? Creo que no sirve el expediente de acudir a un factor aislado (los partidos republicanos o el papel de los intelectuales que predicaban la bondad del cambio de régimen). Para mi, la incógnita no está todavía despejada del todo. Pero era sólo un ejemplo y no se trata aquí de hablar de nuevo sobre el advenimiento de otra (¡una más!) de nuestras ocasiones perdidas.

Tampoco ayuda mucho en la empresa la abundante bibliografia de corte anglosajón que tanta tinta ha hecho correr sobre el paso a la modernización. Aunque yo mismo en un par de ocasiones haya aplicado estos 
esquemas a nuestro país, lo que aún está por demostrar (con perdón para los grandes sociólogos norteamericanos de la política) es que modernización y democracia hayan de caminar juntos. La historia y el presente están llenos de ejemplos que ponen en solfa dicha equiparación. Y, por supuesto, que los dogmáticos del marxismo o del fascismo también se apresurarian a recordarme que lo que tampoco es equiparable es lo de democracia con democracia liberal-capitalista. Allá ellos. No es ocasión ni lugar para polémicas ni análisis comparados. Me limito a afirmar que la cuestión es discutible y que, al menos en nuestro país, esa abundante bibligrafía debe ser utilizada como antaño se clasificaban algunas peliculas por la Iglesia española. Es decir, “con reparos».

Ocurre, además, que, a pesar de haber transitado mucho, tampoco encontramos en nuestra historia política un modelo uniforme de transición. Echando la vista atrás, encontramos que en el tracto 1810-1812, cuando realmente se cambia de régimen y comienza nuestra singladura contemporánea, al cambio lo que antecede es una guerra contra una potencia extranjera y, además, y aunque se llegara a discutir en las Cortes de Cádiz, se mantiene la monarquía aunque se la conciba como monarquía constitucional. En el segundo gran momento, el bienio 1868-1869, sí encontramos una revolución liberal-burguesa pero de nuevo se conserva la institución. Se trataba, como sobradamente se ha apuntado por diversos autores, de sanear mores y acabar con corruptelas. $Y$ en 1931 no existe ningún tipo de acontecimiento traumático (ni revolución, ni guerra) y entonces si se da el paso a la República. Más aún, el supuesto, en principio unido a todo cambio auténticamente rupturista (y ya estamos con el dilema ruptura-reforma que tanto dará que hablar en lustros lejanos y cercanos) de unicameralismo, que aparece con la Constitución gaditana (una es la soberanía, luego una es la cámara que la representa o encarna), quiebra en el texto de 1869 y reaparece en 1931. En la República que, en palabras de JIMÉNEZ DE ASÚA, "venia a cambiarlo todo". Los meandros impiden un criterio uniforme al que agarramos como precedente.

$Y$, como es sabido, todo ello lastrado por pronunciamientos que en buena parte del XIX son de cariz liberal y a fines de dicho siglo y durante los primeros años del que vivimos, se tornan conservadores por los cambios que en la misma institución militar se producen y en los que no podemos detenernos aquí (fin de las guerras coloniales, conexiones del ejército con nobleza y poder económico, concepción del mismo como instrumento para mantener el orden interno, etc., etc.). Y lastrado por caciquismo que, como igualmente por tantas voces se ha puesto de manifiesto, falsea, desde su mismo nacimiento, al sistema representativo español.

Todo esto empaña el precedente que añoramos. Precedente aún más lleno de incógnitas en los casos de tránsitos pacíficos. Aquellos en los que no media revolución alguna. Aquellos en los que, como destacara RAMOS OLIVEIRA para el caso de la segunda República, el cambio se produce «sin pagar el oneroso tributo de sangre que la historia suele exigir a las nacio- 
nes que cambian su forma de gobierno". Las preguntas sin respuestas se acumulan, evidentemente, en estos tipos de transición.

Desprovistos de sólidos asideros en los que asentar nuestro excursus, y carentes de un patrón uniforme al que recurrir, hagamos ya alguna reflexión sobre nuestra última transición a la democracia. La que los españoles vivimos entre los años 1976 a 1978.

Diremos, ante todo, que los años citados y, por ende, el fenómeno mismo de la transición resultan objeto de discusión por lo que a su duración se refiere. Es posible que antes del fallecimiento del anterior Jefe del Estado, algunas cosas hubieran cambiado en el régimen. Pero parece claro que no habia cambiado el régimen. Sin duda, los perfiles del régimen político franquista no son iguales en 1940 y en 1970. Pero hay unos supuestos básicos sobre los que permanentemente descansó el franquismo y que no hubieran cambiado nunca mientras permaneciera su fundador. En otro lugar (España 1939-1975. Régimen politico e ideología) los he estudiado con cierto detalle y no es ahora el momento de volver sobre ellos. Lo «intocable» del régimen (poder personal de Franco, negación de los partidos políticos, centralismo estatal, feroz anticomunismo, etc.) estarian todavía ahí si Franco también lo estuviera. Esto me parece incontestable. Se cedió y se concedió en todo cuanto significó, en cada momento histórico, algo que beneficiaba la permanencia del régimen político establecido. Y nunca en nada que lo pusiera realmente en peligro.

Eso en lo que a la fecha inicial se refiere. Comienzo de la transición con la desaparición de Franco, llegada a la Jefatura del Estado del Rey Juan Carlos, Ley para la Reforma Politica, disolución de las Cortes Orgánicas y del Consejo Nacional del Movimiento. Pero, ¿y final de la transición? Aquí la respuesta no puede ser tan contundente.

Parece válido usar 1978 en cuanto que es el año en que el tránsito a un Estado Social y Democrático de Derecho queda plasmado en el texto fundamental de nuestra Constitución. Antes, por demás, el país había conocido las primeras elecciones realmente libres desde febrero de 1936. Como fechas que significan mucho, valen. Pero para quienes no se quedan solamente en la promulgación de un texto, por importante que éste sea, siempre surge la posibilidad del interrogante: ¿Se acaba de verdad la transición al aprobarse y votarse la Constitución? Ni la mentalidad, ni las actitudes cambian a un ritmo tan rápido.

Hay que sopesar, en este punto, varios extremos. Ante todo, el esfuerzo y el tiempo que la misma Constitución requeria para configurar y convertir en realidad nada menos que una nueva forma de Estado. No digo ya de régimen. De Estado. El tránsito del Estado uniforme al llamado Estado de las Autonomias tenía que ser, necesariamente, obra de años. Posiblemente, para algunos se trate de un camino todavia no terminado. En se- 
gundo lugar, el cambio necesario de lo que, entre nosotros, se llamó durante mucho tiempo la Constitución interna y, más tarde, el marxismo definió como Constitución material. Me refiero, claro está, al cambio de los poderes reales. $Y$ aquí cabrian dos preguntas: a) ¿realmente son otros a partir de 1978? y b) aun siendo los mismos, ihan cambiado su forma de actuación? Pienso que cabe contestar afirmativamente a lo segundo con mucha más fuerza que a lo primero. Sería absurdo pensar que banca, Iglesia o Ejército carecen de poder en la España democrática. Pero entiendo que, de igual forma, sería ciego no aceptar que el modo de defender sus intereses (por lo demás, compatibles con la forma de democracia establecida) es bien distinto. Al menos hasta el instante en que escribo estas reflexiones dicha defensa se ha realizado por los canales legitimamente establecidos y el respeto a la voluntad electoral ha funcionado. $Y$, entre nosotros, ello no es poco. De no ser asi, otro habria sido el país después de un triste 23 de febrero.

Por último, queda el tema de las actitudes y mentalidades. Por alguna suerte de milagro, ¿se tornan en 1978 democráticas? ¡Pues no tiene miga el tema! Personalmente creo que, de quedarnos con esta última variable exclusivamente, con sinceridad habría que confesar que la transición no se ha terminado. Sin duda se acabó por extinción el régimen de Franco. Pero creo que no por extinción, al menos todavia, las mentalidades franquistas. Es decir, las pautas y formas de pensar autoritarias. La socialización política en democracia no es obra de pocos años ni mucho menos. Como también he analizado en otro lugar, sigue siendo una empresa importante y no culminada de la democracia actual. Y lo que me solivianta no es sólo el hecho en sí. Me preocupa el escaso interés o el tenue esfuerzo que por doquier es posible comprobar todavía en no pocas instancias del cuerpo social. Confiemos en que la asignatura deje alguna vez de estar pendiente y que, con el cambio generacional, el panorama permita a los españoles de años venideros ser más optimistas en este punto de lo que lo es el autor de estas páginas. Como en varias ocasiones se ha evidenciado, ese meollo llamado «franquismo sociológico" sigue en gran parte ahí.

Convengamos, por todo lo dicho, que 1978 es importante, pero no definitivo. ¿Lo es 1982 cuando se vive la desconocida experiencia de que un Partido Socialista llega al poder? ¿Lo es el momento, realmente histórico, de nuestra plena incorporación a lo que Europa supone? Afirmar lo primero acaso supone olvidarse del evidente antisocialismo visceral que en nuestros días grandes sectores de nuestra sociedad están poniendo de manifiesto. Lo que, como cualquier "anti» visceral, resulta claramente disfuncional para el sistema. $Y$ agarrarse a lo segundo me parece, de momento, algo precipitado. La incorporación juridica, política y económica a Europa (y volvemos a lo anterior) no conlleva una asimilación inmediata, de la noche a la mañana, de los valores que hoy configuran el proceso integrador europeo. Es suficiente comparar indices de lecturas de libros, 
situaciones de la sanidad, calidad de las enseñanzas universitarias o modernización y funcionamiento de servicios para no caer en el prematuro optimismo.

Entonces, cuándo, se preguntará el lector ante esta auténtica hemorragia de «optimismo" que los anteriores párrafos arrojan.

Legítima pregunta a la que cada cual goza de perfecto derecho para dar respuesta. Creo sinceramente que ya pasó la etapa en la que, en palabras de un sabio profesor, estuvimos «largamente instalados en la transición". Pero atraverse a fijar una fecha concreta y definitiva en la que establecer que la transición a la democracia está cerrada supone un arriesgado evento. Y ello, nada más y nada menos, porque el asunto conlleva la precisión de qué sea, en su conjunto, la democracia. Haber transitado hacia algo definitivamente supone que la meta de llegada está claramente establecida. $Y$ ahí es nada lo que, entonces, se nos viene encima.

Nada menos que en 1920 publicaba Hans KELSEN su conocido trabajo Esencia y valor de la democracia, asestando un duro golpe al concepto liberal de ésta. Revisar los cánones del sistema democrático ha sido empeño casi continuado hasta nuestros dias. Incluso "ponerla al día" era la empresa a que nos invitaba sir Stafford CRIPPS en el título mismo de su obra. $Y$, por no alargarnos en citas y quedarnos con la que más a punto nos viene aquí, el maestro BURDEAU decía que la democracia era, en la actualidad, una filosofía, un modo de vivir, una religión y, casi accesoriamente, una forma de gobierno.

Dejando al margen lo de la religión (que esto es siempre peligroso tema entre los españoles), cabría decir con legitimidad que la transición se ha cerrado en cuanto a lo último citado por el profesor francés: en cuanto forma de gobierno. Aqui las cosas parecen estar claras. En una ocasión resumí esa fórmula en el binomio participación-responsabilidad. Se participa porque se es actor, ciudadano y no súbdito. $Y$ porque el derecho a la participación es de todos, hoy no es concebible la democracia sin que ese "todos" incluya al pluralismo como realidad y como valor. $Y$ todos también responden. Cada cual en su esfera. Lógicamente, más los gobernantes, los que tienen o usan parcelas de poder emanadas de la decisión última de una soberanía popular. Hasta aquí, necio sería negar lo evidente. Nuestra vigente Constitución y las reglas de juego político por ella establecidas han funcionado en estos últimos doce años. El tránsito a la forma política está cerrado y los vicios o defectos que en nuestro país el funcionamiento haya originado serán fallos a corregir, unas veces, o fallos propios del sistema, otras. En ningún caso niegan la formula de gobierno.

¿Pero y lo de la filosofía y el modo de vivir? Aquí es donde, recordando lo anteriormente expuesto sobre actitudes, mentalidades y comportamientos, nos quedan sustanciales dudas. Valga lo ya dicho y quedémonos en la espera y en la esperanza. Sin querer dar lecciones a nadie y sin ser tan osados como para caer en la tentación de exportar el modelo. 
En cuanto que estudioso del tema, tengo para mí que la fecha clave para colocar el cierre está estrechamente unida al momento en que en nuestro país se consolide también un estable sistema de partidos. Como canales fundamentales de participación tienen mucho que aportar al respecto. $Y$ al igual que no hay democracia sin pluralismo de partidos, hemos de ser conscientes que esa realidad sagaz y acertadamente recodada por GARCIA PELAYO, el Estado de partidos, pone en cuestión muchos de los supuestos del viejo esquema de la democracia liberal y condiciona a diario el acontecer político. De aquí la importancia del sistema más o menos estable y consolidado que es posible echar en falta todavía. Si democracia es alternancia en el poder, ¿son ya nuestros partidos realmente fuerzas modernizadas (no conjuntos de notables o plataformas circunstaciales) para garantizar estabilidad del gobierno y estabilidad del sistema? Creo que contestar a esta nada baladi pregunta es, posiblemente, cerrar la etapa de nuestra transición. Como definitivamente quedará cerrada, igualmente, cuando de alguna forma seamos capaces de solventar el tradicional «problema regional», según hemos señalado en otras ocasiones.

Hasta aquí, algunas especulaciones sobre el período que ocupa nuestra transición. Pero hurtariamos un aspecto igualmente importante si no habláramos de las vias o circunstancias que a ella nos han llevado.

$Y$ en este punto, hemos de comenzar espantando los simplismos. $Y$ vayan por delante los dos más al uso. En primer lugar, la transición a la democracia no se produce, como algunos predican ahora, por el hecho de que una fuerte oposición al régimen franquista hubiera acabado con él. Recordemos el hecho de que el anterior Jefe de Estado murió en la cama y a causa de la edad y la enfermedad. Además de la semi-oposición de que antaño hablara LINZ, hubo, por supuesto, una clara y notable oposición al régimen autoritario establecido. Pero es innegable que ni acabó con el régimen, ni creo que en ningún momento lo pusiera en seria posición de peligro. Franco contó, hasta el final, con un conjunto de lealtades ( $y$, entre ellas, la muy importante del Ejército) sin duda no extensible a todos los sectores; pero sin duda, igualmente, lo suficientemente importante, 0 , al menos, lo suficientemente fuerte como para permanecer. Precisamente esto, la permanencia, es lo único que el General tenía como objetivo. Y contra ello, nadie ni nada pudo. No se puede volver a escribir la historia, ni inventarse futuribles («lo que hubiera pasado si»). El régimen se extinguió cuando se extinguió la vida de su fundador, artífice y figura principal. La «lealtad al Caudillo» o «lealtad al Generalísimo», por irracionales que hoy nos puedan parecer, duraron hasta el final y funcionaron siempre. Para unos, el vencedor de una guerra-cruzada. Para otros, el sostén de la paz. Ahi estuvieron. Y fueron capaces de superar aislamientos internacionales, huelgas de trabajadores, revueltas estudiantiles y discrepancias intelectuales o episcopales. 
$Y$, en segundo lugar, no menos simplista es sostener que, muerto el protagonista, se transita y ocurre lo que las potencias extranjeras desean. La afirmación suele referirse a lo que los Estados Unidos quisieron. Sin duda que nos encontramos bajo una zona de influencia en la que la hegemonía de los EEUU es innegable. Pero sin duda, también, que poco arriesgaron las grandes potencias en el evento. Por lo demás, el hecho nada tiene de novedad. Poco había arriesgado durante la guerra civil, poco tras el final de la segunda guerra mundial (los embajadores acabaron por volver para humillación de ellos y vanagloria de Franco). Por contra, mucho empeño en el envío del turismo salvador en años de crisis, mucho en la firma del Concordato con el Vaticano y más todavía en los acuerdos militares y económicos con los EEUU, a la postre, el gran valedor para que España, la España de Franco, entrara en la ONU. El régimen se había lavado la cara con leyes semánticas y democracia orgánica, postergado a Falange y asentado un capitalismo monopolista que a dichas potencias extranjeras convenia. Con eso fue suficiente. Entonces, ¿por qué iba el Pentágono a tomarse excesiva preocupación en el logro de nuestra democracia? ¿Se la tomó y sigue tomando en Hispanoamérica? ¿Es que nos hemos olvidado de la asepsia de «cuestión interna» que utilizó luego, ante el fallido intento de golpe de Estado del 23 de febrero? Seamos realistas. Para los EEUU somos «algo», solamente eso, en su enorme política exterior. Cualquier ciudadano español que, al visitar los EEUU, haya tenido que aclarar que es spanish de España y no de “Latinoamérica» comprenderá lo que digo y se despojará al instante de nuestra ancestral tentación de considerarnos ombligo del mundo. Las bases militares, que ya tenian y en mejores condiciones, era lo realmente importante. $Y$ con las bases, las multinacionales.

Despejados ambos simplismos, no caigamos nosotros y aquí en otro, antes de exponer lo que consideramos fundamental. La transición a la democracia tuvo unos impulsos colaterales que no es posible olvidar. Insisto, sin que lograran acabar con el franquismo. Pero, en mayor o menor medida, algo pesaron. O algo prepararon el camino. Como se quiera. Hablamos de un conjunto de factores que seria ahora largo detallar. Largo y complicado. Porque, para seguir espantando simplismos, ocurrió que incluso el Régimen llegó a asumir algunos de ellos. No olvidemos: lo importante era permanecer.

Entres esos factores, que algunos estarian tentados de considerar como «pre-requisitos" y que nosotros, tras estudiar a fondo la evolución del franquismo, colocamos en un plano en absoluto modificadores del Régimen; entre ellos, digo, cabe señalar la evolución de parte de la Iglesia española tras lo que supuso Juan XXIII y el Concilio Vaticano, la misma influencia del turismo, ciertas exigencias del nuevo capitalismo en provecho de sus intereses, paulatino asentamiento de una generación que ya no conoció la guerra civil, distanciamiento de algunos intelectuales, meritoria tarea de cierta parte de la prensa con el paso de Fraga por el Ministerio 
de Información (al César lo que es del César) y quizá algún factor más que ahora dejo en el tintero.

Todo eso influyó. A mejor decir: confluyó. Pero nada más. Como antes insinuaba, el franquismo se apresuró a asumir algunos de ellos. $Y$ del nacional-catolicismo se pasó al catolicismo tecnocrático y capitalista (¿son compatibles? se preguntaria un cristiano de Evangelio). $Y$ del monolitismo a las «asociaciones políticas». Siempre hubo quien se prestó a jugar el juego de lavar la cara al Régimen. Siguiendo intocable lo que la exclusiva voluntad del General hacía muhco tiempo que había considerado y proclamado intocable. Sin que nadie se moleste, sin afán de triunfalismo nostálgico (ni edad, ni ideología me pueden hacer sospechoso de ello) y sin ninguna infravaloración: por mucho Tarancón o por muchas Comisiones Obreras que se hubieran producido, estando Franco con vida nunca habrian sido admitidos los partidos políticos, jamás el Partido Comunista, nunca las elecciones realmente libres y jamás la auténtica descentralización política. Por ende, reconozcamos a los factores el valor que realmente tuvieron ( $\mathrm{ni}$ más, ni menos). $Y$ vayamos de una vez al grano. $O$, al menos, a lo que consideramos nosotros que fue el grano.

Entendemos que, además de la coincidencia de factores antes citados, fundamentalmente la transición pacífica de España a la democracia tuvo dos pilares básicos.

En primer lugar, la existencia y consolidación, acaso por vez primera en la historia político-social de nuestro país, de una amplia clase media de corte burgués. Una nutrida burguesia, asentada en pautas de consumismo, mediano capitalismo y cierto espiritu inversor. Algo de lo que, sin duda por desdicha, nuestro país careció en 1936, momento trágico en el que realmente lo que chocan son las dos versiones hechas realidad de un dilema inicial y meramente especulativo. Lo que chocan, enfrentan y mueren son dos Españas. Pienso que es dificil combatir la imagen de una segunda República claramente escindida entre quienes todo lo tenian y entre quienes no tenian nada. Los remedios republicanos no sirvieron o no tuvieron tiempo para evitar el enfrentamiento. En nuestra última contienda civil, aunque se revistiera de esto o aquello (Cruzada, Movimiento Nacional, Alzamiento, etc.), lo que se dio es el crudo enfrentamiento de dos formas de entender España y, sin duda, de dos formas radicalmente incompatibles de poseerla. Faltó ese colchón intermedio que evitara el enfrentamiento entre los extremos.

Por el contrario, durante los años sesenta y comienzos de los setenta, las pautas capitalistas de lo que un día di en llamar el «franquismo tecno-pragmático», originan y sedimentan esa nueva clase social que tenia dos objetivos bien definidos: conservar a ultranza los niveles económicos obtenidos y, lógicamente, alejar cualquier asomo de una nueva contienda en la que «se pudiera perder algo». LÓPEZ PINTOR hace algunos años ( $L a$ 
opinión pública española: del franquismo a la democracia, 1982) y muy recientemente, siguiendo sus pasos, RODRÍGUEZ DIAZ (Transición política y consolidación constitucional de los partidos politicos, 1989), entre otros, han abundado en las caracteristicas de este sector social.

Para esta nueva burguesía importaba poco la veracidad de la ideología oficial imperante. Era una burguesía definida fundamentalmente por su mentalidad: miedo a perder lo obtenido en los años de las vacas gordas (coche, piso, veraneo, etc.), miedo a la pertubación del orden público, tanto por el pánico al desorden cuanto por lo que su aparición podía acarrear, miedo a una posible falta de autoridad, miedo a unos nuevos enfrentamientos de clases, miedo al caos. El miedo reforzó el ingrediente conservador. Lo que el franquismo habia garantizado hasta entonces, tenia que garantizarlo lo que viniera después. Daba igual lo que viniera y estaba claro lo que tenía que ser garantizado. Nadie creía en la «conspiración judeomasónica" y casi nadie (aunque sólo fuera por tener la menor. referencia de cómo funcionaban otros paises) asumía aquello de que los partidos políticos eran "intrínsecamente perversos", como por extraña paradoja de la vida política en una ocasión defendiera quien luego iba a ser encargado de disolver las Cortes orgánicas.

Este primer pilar estuvo integrado, además, por quienes, generacionalmente, ya no habían vivido la mentalidad de cruzada anti esto y aquello propia de «quienes hicieron la guerra». Se habian cerrado cicatrices a pesar de que el Régimen se empeñara en abrirlas de vez en vez. Es decir, cuando le convenía. Los intelectuales afines al régimen agotaron inútiles esfuerzos en dar cuerpo ideológico y apariencia constitucional a lo que, al final, nadie creía en serio. Hasta el más puritano de los párrocos de las zonas turísticas españolas cedió en la lucha contra el bikini de la extranjera que dejaba divisas. La especulación del suelo se impuso a la llamada «justicia social». Y el «Genio de España» o las razones de la «España eterna» (por utilizar títulos que ya nada decian), sucumbieron ante el capitalismo que se veía en el cine o aparecía en la pequeña pantalla hogareña. El bingo reunía más gente que las novenas, y el resultado de un partido del Real Madrid fue muy pronto mucho más importante que los resultados de las llamadas elecciones de los procuradores familiares. Así fue. Por miedo, por afán de conservar y por pura conveniencia.

De esta clase social burguesa se pueden deducir todos los defectos que se quiera. Incluso, para los iluminados de ambos extremos, sin duda aquello resultaba triste. Como luego iba a resultar aburrida la democracia que se establecía. Pero, se quiera o no, entre «los discretos encantos» de aquella burguesia (pienso que todavia hoy con parecida mentalidad) pudo incluirse el deseo de que el cambio fuera pacífico y de que dos familias españolas no se enfrentaran sangrientamente de nuevo. Para mí, bienvenida era. En su mera existencia estuvo una de las claves para entender to que a partir de noviembre de 1975 iba a pasar en España. 
Porque, y esto resulta evidente también para cualquier estudioso objetivo de la realidad de aquellos momentos, ocurrió, además, que muchas de esas pautas descritas fueron asumidas por amplios sectores de la clase trabajadora. El esquema dialéctico del marxismo ortodoxo resultaba cada vez menos aplicable a la situación. Los intereses a defender, aun partiendo de contextos en principio claramente diferenciados, llegaban a confluir. Acaso es que lo de la conciencia de clase alcanzó niveles de difusión. 0 acaso fuera que primaban objetivos más inmediatos y más tangibles entre lo, en principio, teóricamente separado. Si la nacida burguesía asumía y practicaba valores y pautas capitalistas (posiblemente sin serlo), gran parte del proletariado hacía otro tanto con valores y pautas burguesas (sin ser los que de dichos sectores cabia esperar desde dicha visión dialéctica). $Y$ es que las vacas gordas vinieron para todos. La espita de la emigración y el posterior regreso alivió no poco las distancias y alejó el fantasma de los traumas. La mayoria de las protestas tuvieron un carácter meramente reivindicatorio y pienso que la «conciencianción» (y perdón por la palabreja al uso) fue posterior. Posterior y, en buena medida, fomentada desde arriba, desde los luego legales sindicatos. Por ahí puede venir alguna explicación a los escasos niveles de sindicación que todavía en la actualidad cabe comprobar en nuestro país.

En suma, lo que, en el discurso teórico, estaba llamado a chocar no choco. Tampoco el trabajador quería ver en riesgo unos ciertos niveles adquiridos en épocas de economia floreciente. Esas épocas que, por triste ironia de la historia, casi siempre han acompañado a etapas autoritarias (algo similar ocurrió en los «felices años 20" con la dictadura de Primo de Rivera), en tanto que la llegada de las etapas democráticas han solido coincidir con periodos de crisis (no olvidemos que, al proclamarse la segunda República, llegaba a Europa el eco de la caída de la bolsa de EEUU). Triste ironia que ha hecho siempre más dificultosos los primeros pasos del régimen democrático entre nosotros. iY eso que estamos en la predilecta tierra de María Santísima, según el nacional-catolicismo que a la sazón imperaba!

La mentalidad descrita fue en gran parte generalidad. Como generalizada fue la pancorrupción que en otros trabajos hemos descrito. Dos premisas que explican no sólo lo que pasó, sino también gran parte de lo que iba a pasar algunos años después. Pero como bueno es lo que bien acaba, pongamos los ojos en cuanto de positivo tuvo este primer pilar que brevemente hemos diseñado.

$Y$, en segundo lugar, otro pilar que nos parece aún más importante. Me refiero al papel desempeñado por la Monarquía establecida. Por supuesto que comienzan ya a no ser escasos los estudios sobre nuestro estilo de Monarquía y su análisis desde el punto de vista jurídico y constitucional. Las aportaciones de Miguel HERRERO RODRÍGUEZ DE MIÑON, o del Prof. BAR, por ejemplo, nos merecen el mayor elogio. Pero o mucho me equivoco o todavia no se ha profundizado (acaso por comprensible respeto a tan alta 
institución) el complicado camino que en los momentos de la transición desempeñó la figura del Rey, ni las posturas han sido clarificadas. Diria más. Creo que, por las razones que fueren, ciertas posiciones iniciales se han condenado al olvido. $Y$ creo que para el científico de la política no es correcto ese camino sea cual sea su óptica política. Para aviso de navegantes, dejo constancia por adelantado del profundo respeto y la sincera lealtad que la figura y la obra del actual Rey me merecen. Pero, acto seguido, conviene que, como estudioso de la sociedad española, no me limite a la trillada afirmación de que el Rey fue el motor del cambio (que en gran parte lo fue) y me detenga en los supuestos de partida.

En esa línea, lo primero que hay que decir es que, a finales del franquismo, nadie o casi nadie era auténticamente monárquico. Es decir, monárquico por convicción. Monárquico por creer que la persona del llamado a suceder a Franco en la Jefatura del Estado, les pareciera tanto un indiscutible simbolo de continuidad con un pasado tradicionalmente monárquico, cuanto una absoluta garantía de que, a través de él, el futuro pacífico de una democracia moderna estaba garantizado. Casi nadie. $Y$ pienso que gran parte de las afirmaciones en sentido contrario, se oponen a la verdad. Me explicaré.

La Monarquía borbónica había sido fuertemente herida por el propio Régimen de Franco. Y ello a través de varios y continuos caminos. Por la clarísima oposición del General a que el legítimo heredero, el Conde de Barcelona, fuera alguna vez propuesto como Rey. Por la no menos clarísima aversión que los grupos que inicialmente sostienen al Régimen, especialmente falangistas y tradicionalistas, manifestaron hacia «los borbones». Nadie que en los años cuarenta o cincuenta tuviera que padecer aquellas clases de una asignatura llamada «Formación del Espíritu», habrá olvidado los abiertos ataques de los profesores (de la Falange, SEU o Movimiento) hacia dicha dinastía. Ataques que llegaban con facilidad al insulto y que, sobre todo, intentaban conectar la idea de posible monarquía al pasado de Isabel y Fernando. En la caída de los austrias y en la llegada de los borbones se cifraban gran parte de los "males de la patria". Porque el mismo Régimen sostuvo siempre la ambigüedad de la llamada «Monarquía tradicional», sin duda como oportuno reclamo hacia los tradicionalistas. No se olvide que la fusión de FET y de las JONS se quedó desde el comienzo en el papel y que los Ilamados carlistas pronto así lo hicieron ver. Porque, incluso después de proclamada la persona del sucesor a título de Jefe del Estado, se mantuvieron las intrigas para que el General cambiase de opinión. No faltaron candidatos ni conexiones familiares. $Y$, en fin, porque en algunos sectores del Ejército (a la postre, ahi estaba la última palabra tras el 20 de noviembre de 1975), la persona del actual monarca no gozaba precisamente de muchas simpatias. Las adhesiones no pasaban de ser fríos acatamientos a la voluntad del Caudillo: porque lo habia querido y proclamado el Generalísimo. No mucho más. Creo que conviene recordar todo esto antes de llegar a la valoración final. 
Por otra parte, para la mayoría de los españoles, la institución monárquica como fórmula de régimen era algo «poco entusiasmante». En parte, no habia vivido en régimen de monarquía. En parte, el asunto parecía algo que sonaba a pasado (intrigas palaciegas, "borboneo», títulos de nobleza, carrozas, etc.), algo que «ya no era de estos tiempos». En parte, porque el mero argumento del principio hereditario como fundamento único para "mandar» en un país, estaba muy lejos de ser asimilado. Más bien, lo contrario. $Y$ en parte, en fin, porque era impensable (repito, impensable) que, para quienes no gustaban del franquismo, algo (persona, sistema) pudiera desembocar en democracia una vez desaparecida la figura del General. Los pequeños reductos quedaban en Estoril y se esparcian por un no muy numeroso grupo de politicos o intelectuales que, por lo demás, insistieron hasta el final, hasta la evidencia de lo imposible, en la persona de D. Juan.

A estos sectores falta por sumar otro que, deliberadamente, tratamos por separado. Me refiero a quienes, en principio, es previsible pensar que estaban abiertamente dispuestos a admitir, aplaudir y sostener a una Corona que había sido «instaurada» (nunca se aceptó lo de «restaurada») por el mismísimo Franco. Es decir, una Monarquía llamada a ser la Monarquía del Movimiento Nacional. La de la continuidad de unos Principios Fundamentales que habian servido de soporte al régimen de Franco. En principio, insisto, los amplios sectores del régimen franquista había que suponerlos apoyando el mecanismo de recambio establecido por «el Caudillo». Nada iba a cambiar, luego nada había que temer. Sin embargo, tengo para mí, que ni siquiera en esos sectores la Monarquía de D. Juan Carlos era bien vista. $O$, al menos, "no era del todo de fiar". Ciertamente que, a nivel legal, todo quedaba atado y bien atado. Parecía poco menos que un milagro la empresa de desatar. pero esto era en principio. En el fondo de la ideología y mentalidad franquistas, se daban tres circunstancias para que, en la realidad, no fuera así. Ante todo, la profunda socialización política en valores anti-borbónicos a que antes nos hemos referido. Aunque no se explicitara por los franquistas, seguían sin ser monárquicos a pesar de la decisión de Franco. Al Caudillo había que obedecerle ciegamente hasta que pronunciara su última palabra. Pero luego, ya se vería. A ese recelo fuertemente alimentado desde la infancia, acompañaba una especie de incapacidad natural que se atribuía, sin razón alguna, al llamado a la sucesión. Estaba por ello condenado a fracasar y durar poco. En segundo lugar, los protagonistas del Régimen eran conscientes de que todo podia entrar en cuarentena al desaparecer su fundador. Solamente la persona de Franco era capaz de unir lo difícilmente unible, de obtener lealtades «inquebrantables", de que cada grupo se apresurara a tragarse «su verdad» si «la verdad» del Geneal victorioso de una cruzada y artífice de larga paz, era otra. Únicamente en Franco estaba vitaliciamente la unidad de poder. $Y$, aunque mostraran lealtad pública, los propios franquistas eran conscientes de que el régimen de Franco se acababa con él. De aqui el conocido ¿y después de Franco qué? que tanto preocupaba. $Y$ de aquí igualmente que nadie apos- 
tara, que posiblemente ni el franquista más convencido apostara seriamente por la certeza de la respuesta oficial al uso: «después de Franco, las instituciones". Por último, esta desconfianza estuvo desde siempre unida y basada en algo todavía no profundamente analizado, pese a ser algo tan natural. Me refiero a la relación del entonces Príncipe heredero con su padre. O lo que es lo mismo, el temor a la influencia que el padre podía haber ejercido sobre el hijo y la que pudiera aperar llegado el momento de la sucesión en la Jefatura del Estado. D. Juan Carlos, todavía Príncipe heredero, había vivido bastantes años entre dos influencias claramente contrapuestas. Y eso no era del todo fiable. ¿Por cuál de ellas optaria desaparecido Franco y una vez convertido en Jefe del Estado? Esta pregunta sin respuesta despertaba recelos, enfriaba entusiasmos y restaba adhesiones.

Como hemos resumido (el tema, por sugestivo, mereceria mucho más espacio), no era mucho el soporte social con el que la Monarquía establecida tendría que dar sus primeros pasos. Tanto más cuanto la mayoría de las fuerzas de la oposición, en los momentos en que la transición comienza, le niegan igualmente el pan y la sal. La diseñada imagen de una Monarquía franquista no podía ser aceptada por liberales, democristianos, socialistas ni comunistas. De aqui que la sombra de ensayar de nuevo la República estaba en el deseo y en los programas de muchos. Quedaban republicanos obligados al exilio exterior o interior. Quedaba, incluso, la nostalgia política de efectuar algún tipo de reparación a lo que un 18 de julio fue ahogado traumáticamente. La «tradición republicana» se mantenía y enarbolaba por distintas fuerzas. $Y$ se autoalimentaba al pensar «el tipo de Monarquía» que Franco legaba al futuro.

¿Hacia dónde mirar entonces? ¿Con quién conectar? ¿Aceptar el legado u olvidarse de él? Si se optaba por lo primero, ¿cuánto tiempo duraria la institución? Si por lo segundo, ¿con qué apoyos? ¿Qué actitud adoptaria un Ejército que habia perdido a su Generalísimo? Puestos a cambiar de rumbo, ¿de qué forma hacerlo? Surgía de nuevo el dilema reforma-ruptura. ¿Cambiar desde dentro? ¿Llamar a los de fuera? ¿Dónde estaba la decisiva influencia y dónde el consejo sobre el método a seguir? Pienso que, a las alturas de hoy, nada más insensato que sostener los argumentos de casualidad, comodidad o suerte. En la vida politica de los pueblos, la suerte suele ir unida a factores personales o colectivos bien definidos. Lo adecuado, lo razonable es afirmar que la empresa no era nada fácil. Que el riesgo iba a ser muy alto se hiciera lo que se hiciera y que era y fue preciso unir coraje con astucia. Valor con prudencia. Negar esto es, sencillamente y entre los españoles de la actualidad, negar la evidencia histórica.

¿Cómo sé resolvió el dilema? Entramos en el punto más discutible y escurridizo de toda la cuestión. Sin duda también el más sugestivo. El punto en el que al investigador distante le hubiera gustado ser espectador cercano. Como no fue asi en quien estas líneas escribe, lo ủnico que cabe 
es aventurarse en la empresa de lanzar la interpretación que parece más adecuada.

$Y$ entiendo que, en aquellos cruciales meses de la transición, el Rey tomó dos opciones y eligió un camino.

La primera opción consistió en la de apostar claramente en favor de la instauración de un régimen democrático para España. De esta forma, conectaba con un amplio sector y una extendida demanda de la sociedad española, colocaba a España a la altura de los tiempos y la misma Monarquía encontraba una vía de mayor justificación como luego señalaremos.

La segunda opción consistió en hacerse eco de ese cambio pacífico, sin trauma, sin riesgos, que, según hemos analizado anteriormente, era la nota dominante en la ya abundante sociedad burguesa española. Asi, su figura pasaba también a ser la garantía de la estabilidad en lo conseguido.

$Y$ eligió el camino de realizar el cambio desde las mismas estructuras institucionales y legales existentes. Se buscan personas claramente unidas al Movimiento (Fernández Miranda, Suárez), se elabora y aprueba una Ley para la Reforma Política que es sometida a la aprobación del pueblo español (no olvidemos que parte de la oposición todavía aconsejaba la abstención), se autodisuelven Cortes Orgánicas y Consejo Nacional de Movimiento. Se consigue, mediante este camino, que la propia voluntad soberana haga desaparecer el aparato institucional del franquismo. La pureza del método elegido cerraba el paso a acusaciones de diversa índole y aquietaba las actitudes. Enfrentarse a ese camino, una vez aprobada la Reforma Política, era, sencillamente, enfrentarse no ya a la persona del Rey, sino a la mayoritaria voluntad de la nación. Es cierto que hubo gestos. Pero nada más. Nadie movió un dedo en contra.

Creo que no cupo mayor acierto en las opciones y en el camino. Muy pronto, incluso los tradicionales partidos de «inspiración republicana», se doblegan ante la evidencia. Una Monarquía que se separa abiertamente del inmediato pasado. Un Rey que manifiesta querer serlo «de todos los españoles" (se acaba el ostracismo de la famosa "anti-España»). $Y$ una institución que desde ese instante se convierte en motor del cambio. Años más tarde, cuando el fracasado intento de golpe de Estado, la palabra ya no es sólo motor. La palabra es también garantía. Cualquiera que piense en quién pusieron ojos y oídos los españoles aquella famosa noche del 23 de febrero, coincidirá en lo que digo. Sólo ante la presencia y gestión del Rey fueron convencidos muchos jefes militares. Sólo por una lealtad, ya constitucional, a quien era su Jefe Supremo, se salvó, en aquel instante, la democracia pacífica. Otra cosa bien distinta (volvemos a los futuribles) es qué hubiera pasado de no funcionar este mecanismo de garantía. ¡Vaya usted a saber! En cualquier caso, en aquel instante sólo estaba el Rey. 
$Y$ hechas estas opciones y transitado por este camino, el resto vino por añadidura. La Monarquia parlamentaria se plasma en nuestro texto constitucional, no sin tener que vencer algunas resistencias y no sin que el mayor partido de la oposición, el PSOE, llevara a cabo la patriótica renuncia de uno de sus principios tradicionales. De ello me acabo de ocupar en un muy reciente libro al que remito al lector interesado (Partidos Politicos y Constitución. Un estudio de las actitudes parlamentarias durante el proceso de creación constitucional. Centro de Estudios Constitucionales, 1989). Y al aprobarse nuestro texto fundamental por la mayoria del pueblo español, la institución añadía a sus legitimidades de origen (el Conde de Barcelona permite que asi sea con otro gesto loable) y de naturaleza inspiradora del cambio, la que hasta entonces estaba jurídicamente ausente: la del refrendo democrático por voluntad popular.

Ciertamente que, para que la obra terminase bien, fueron precisas otras ayudas. Lealtad del Ejército, insoslayable papel de Fraga en la reconducción de grandes sectores del extinto franquismo al sistema democrático, no menos valiosa labor de Carrillo en la configuración de un Partido Comunista que rompe con mucho y acepta Monarquia, bandera, etc. $\mathrm{Y}$, sin duda también, impagables esfuerzos de Suárez por «templar gaitas" y parar posturas de muy variado signo. De todo ello no debe olvidarse la historia. Pero nada debe restar importancia tampoco al segundo pilar, la Monarquía, que supo ser pionera y marcar el rumbo de la difícil singladura llamada transición. 